\title{
Processos, dinâmicas, relações
}

\section{Apresentação}

Caras leitoras e leitores,

A Equipe Editorial da Revista Cadernos de Pesquisa Interdisciplinar em Ciências Humanas, vinculada ao Programa de Pós-graduação Interdisciplinar em Ciências Humanas da Universidade Federal de Santa Catarina, apresenta o volume 16, número 109, correspondente ao segundo número semestral de 2015, intitulado Processos, dinâmicas, relações.

Os artigos que formam o presente número dizem respeito a temas e perspectivas de análise que convidam a refletir sobre questões prementes: o processo de industrialização e urbanização e as consequências para o meio ambiente e para os trabalhadores. O conhecimento socialmente produzido e as formas de inclusão e exclusão. O papel do Estado como garantidor de direitos através do sistema de administração de justiça. A importância da história e da memoria.

Reafirmando o nosso compromisso com a divulgação qualificada do conhecimento e com o fortalecimento de um projeto editorial interdisciplinar de qualidade, convidamos todas e todos à leitura.

Cordiais cumprimentos da Equipe Editorial,

Maria del Carmen Cortizo

Catarina Nascimento de Oliveira

Leonardo de Miranda Ramos

Marinês Rosa

Morgani Guzzo

Patrícia Kozuchovski Daré

Rebecca Corrêa e Silva

Vera Fátima Gasparetto 